\title{
PODER NORMATIVO DAS AGÊNCIAS REGULADORAS NORTE-AMERICANAS
}

\author{
LEILA CUÉLlaR ${ }^{1}$
}

1. Introdução. 2. Direito administrativo norte-americano e agências administrativas. 2.1. Noção de direito administrativo para o direito norte-americano. 2.2. Noção de agências administrativas 2.2.1. Conceito. 2.2.2. Classificações. 2.3. Evolução do direito administrativo norte-americano. 3. $O$ poder normativo das agências reguladoras norte-americanas. 3.1. Delegação de poderes. 3.2. A atividade normativa das agências reguladoras. 3.2.1. Noção de regulamento. 3.2.2. Classes de regulamentos. 3.2.3. Procedimentos normativos. 3.3.4. Consideraçóes acerca da atividade normativa. 3.3.4.1. Princípio da informação. 3.3.4.2. Principio da participação. 3.3.4.3. Princípio da responsabilidade ("accountability"). 4. Considerações finais. Referências bibliográficas.

\section{Introduçāo}

Nos últimos anos, especialmente a partir de 1995 (após a edição da Emenda Constitucional $n^{\circ} 5 / 95$ ), o governo brasileiro iniciou processo de reforma do Estado, visando a superar a crise em que se encontra, reconstrui-lo e fortalecê-lo. ${ }^{2}$

1 Procuradora do Estado do Paraná e Professora Titular de Direito Econômico do Centro Universitário Positivo - Unicenp. Mestre em Direito Econômico - UFPR, Doutora em Direito Administrativo - UFPR, Pós-graduação em Regulação Pública realizada no Centro de Estudos de Direito Público e Regulação da Faculdade de Direito da Universidade de Coimbra no primeiro semestre de 2002.

2 Ampliar em Luiz Carlos Bresser PEREIRA. Reforma do Estado para a cidadania: A reforma gerencial brasileira na perspectiva internacional. São Paulo: Editora 34. 1998, p. 31. 
Dentre as medidas adotadas está a criação das agências reguladoras, ${ }^{3}$ autarquias sob regime especial, com personalidade jurídica de direito público e autonomia patrimonial. administrativa e financeira, cuja função primordial é a regulação de atividade econômica. ${ }^{+}$principalmente através da normatização, fiscalização e controle de atividades desenvolvidas pelos particulares.

Como as agências administrativas norte-americanas serviram de inspiração para a instituição e regulamentação das agências reguladoras brasileiras, sendo usualmente consideradas as primeiras agências desta espécie no mundo, é imprescindível que se proceda à análise das mesmas, para melhor se compreender o instituto recentemente introduzido no ordenamento jurídico brasileiro. Ademais, ao que tudo indica, a denominação "agência reguladora", adotada pelo legislador nacional, inspirou-se nos termos empregados pelo direito norte-americano: "independent administrative agencies" ou "regulatory agencies".

Tendo em vista que uma análise acerca das agências norte-americanas pode ser bastante ampla, precipuamente pelo fato de que constituem o objeto principal do direito administrativo estadunidense, o presente estudo abordará em especial tema específico: o poder normativo de tais agências.

O trabalho é dividido em duas partes. A primeira aborda a noção e evolução do direito administrativo e das agências administrativas norte-americanos e a segunda versa sobre o poder normativo das agências, abrangendo tópicos relativos à delegação de poderes. aos procedimentos normativos e aos princípios orientadores do processo normativo.

É imperioso frisar que este trabalho possui natureza descritiva, objetivando auxiliar para o estudo da nova ordem administrativa que se instala no Brasil com as liberalizações, privatizações (em sentido amplo) e a instituição das agências reguladoras.

3 São exemplos das novas agências: ANEEL - Agência Nacional de Energia Elétrica. criada pela Lei $n^{\circ}$ 9.427. de 26.12.1996 c implantada pela a Lei $n^{\circ}$ 9.648. de 27.05.1998: ANATEL - Agência Nacional de Telecomunicações, (Lei $n^{\circ}$ 9.472, de 16.06.1997: Decreto $n^{\circ} 2.338$, de 7.10.97); ANP - Agência Nacional do Petróleo (Lei n ${ }^{\circ}$ 9.478, de 06.08.1997 e Decreto $n^{\circ} 2.455$, de 14.01.1998); ANVISA - Agência Nacional de Vigilância Sanitária (Lei $n^{\circ} 9.782$, de 26.01.1999 e Decreto $n^{\circ}$ 3.029. de 16.04.1999): ANS - Agência Nacional de Saúde Suplementar (Lei $n^{\circ}$ 9.961, de 28/01/2000: Decreto ${ }^{\circ}$ 3.327, de 05.01.2000): ANTT - Agência Nacional de Transportes Terrestres (Lci $n^{\circ}$ 10.233. de 05.06.2001); ANTAQ - Agência Nacional de Transportes Aquaviários (Lei $n^{\circ}$ 10.233. de 05.06.2001): ANCINE - Agência Nacional do Cinema (MP n 2228-1, de 06.09.2001, CVM (transformada em agência reguladora através da Lei $\mathbf{n}^{\circ} 10.411$, de 26.03.2002). Para acesso à maioria das normas relativas às agências estaduais e municipais. confira-se no endereço eletrônico da Associação Brasileira das Agências Reguladoras - www.abar.org.br.

4 Acerca da noção de regulação deve-se conferir as lições de Vital MOREIRA, que assim destaca: "Como se disse. o conceito de regulação exclui a actividade económica do Estado (o Estado produtor). A regulação é scmpre um condicionamento externo á actividade dos agentes económicos." (Auto-regulação profissional e administração pública. Coimbra: Almedina, 1997. p. 37.) 


\subsection{Noção de direito administrativo para o direito norte-americano}

No Direito norte-americano a noção de direito administrativo está atrelada à de agências administrativas. A doutrina concebe o direito administrativo como conjunto de normas e princípios que definem os poderes e a estrutura das agências administrativas, especificam as formalidades procedimentais a serem adotadas por elas, determinam a validade das decisões por elas proferidas e fixam o papel a ser desempenhado pelos Poderes Executivo, Legislativo e Judiciário no controle da atuação das agências. ${ }^{5} \mathrm{O}$ direito administrativo norte-americano compreende, principalmente, o papel das agências administrativas na sociedade e seus poderes na implementação de políticas públicas. ${ }^{6}$

Para WARREN, o direito administrativo cinge-se às formas pelas quais o Poder Legislativo delega poderes às agências administrativas, ao modo como elas os utilizam, bem como ao controle exercido pelo Poder Judiciário. Salienta o autor que o direito administrativo norte-americano hodierno se preocupa particularmente com o crescimento das denominadas funções "quase-legislativa" e "quase jurisdicional" dos referidos organismos administrativos. ${ }^{\text {? }}$

Sucintamente, portanto, poder-se-ia concluir que o direito administrativo estadunidense é o ramo do direito que se refere às agências administrativas: sua criação, incumbências, funcionamento e poderes.

É oportuno destacar pelo menos duas diferenças importantes entre o direito administrativo norte-americano e o brasileiro. ${ }^{8}$ A primeira concerne ao seu objeto.

5 "Administrative law consists of those legal rules and principles that define the authority and structure of administrative agencies, specify the procedural formalities that agencies employ, determine the validity of particular administrative decisions, and delineate the role of reviewing courts and other organs of govemment in their relation to administrative agencies". (Breyer, Stephen: Stewart. Richard B. Administrative law and regulatory policy: Problems, text and cases. 3.ed. [S.I.] Little, Brown and company, p. 3.). Definição semelhante é apresentada por Bonfield e Asimow (Bonfield, Arthur E.; Asimow, Michael. State and federal administrative lan: St. Paul: West Publishing Co., 1989, p. 2.).

6 Nesse sentido são as lições de Lawson. (Lawson, Gary. Federal administrative law. St. Paul: West Group, 1998, p. 1.).

7 "Broadly speaking, administrative law deals with (1) the ways in which power is transferred from legislative bodies to administrative agencies: (2) how administrative agencies use power; and (3) how the actions taken by administrative agencies are reviewed by the courts. More specifically, administrative law is concerned with the legal developments which have so dramatically increased the powers and scope of the administrative branch. The law-making (technically, quasi-legislative or rule-making) and judicial (technically, quasi judicial or order-making) powers, which have been delegated to administrators by the legislative branch at both the national and state levels, have created an extremely powerful administrative branch [...]:" (Warren, Kenneth F. Administrative law in the political system. 3.ed. Upper Saddle River: Prentice-Hall, 1996. p.10.) No mesmo sentido, Bernard Schwartz. Admmistrative law: 3.ed. Boston: Little. Brown and Company, p. 1. 
Enquanto no direito norte-americano o direito administrativo se restringe a matérias relacionadas com as agências administrativas, no Brasil o âmbito do direito administrativo é mais amplo. ${ }^{9}$ Desse modo, várias matérias contidas pelo direito administrativo pátrio, nos Estados Unidos integram disciplinas diversas. ${ }^{10}$

Outra distinção relevante tange à peculiaridade do sistema legal norte-americano sistema da common law. Sendo a jurisprudência a principal fonte do direito, o direito administrativo estadunidense está embasado fundamentalmente nas decisões proferidas pelos órgãos do Poder Judiciário.

\subsection{Noçâo de agências administrativas}

\subsubsection{Conceito}

Considera-se agência administrativa o ente governamental encarregado de administrar e implementar uma determinada legislação, em atendimento ao interesse público nela definido."

Para o Administrative Procedure Act ( $A P A)$, lei norte-americana de procedimentos administrativos, agência é "autoridade do governo federal, distinta do Legislativo e Judiciário...". ${ }^{12}$

8 Ressalta Schwartz, igualmente, que nos Estados Unidos da América não existem tribunais especializados, ao contrário do que ocorre na França. (Schwartz, p. 1 e 2.)

9 De acordo com Maria Helena Dinlz, o direito administrativo é o "Conjunto de normas concernentes: à ação governamental; à organização e realização de serviços públicos destinades a satisfazer um interesse estatal; à instituição dos órgãos que os executam; à capacidade das pessoas administrativas; à competência no exercício das funções públicas; às relações da Administração com os administrados; e à proteção recursal das garantias outorgadas aos cidadãos para a defesa de seus direitos." (Diniz, Maria Helena. Dicionário jurídico. Vol. 2. São Paulo: Saraiva, 1998, p. 139.) Maria Sylvia Zanella Di Pietro precisa que o direito administrativo é "o ramo do direito público que tem por objeto os órgãos, agentes e pessoas jurídicas administrativas que integram a Administração Pública, a atividade jurídica não contenciosa que exerce e os bens que se utiliza para a consecução de seus fins, de natureza pública." (Direito administrativo. $10^{\mathbf{a}}$ ed. São Paulo: Atlas, 1999, p. 47.)

10 Assim, por exemplo, nos Estados Unidos os temas que versam sobre servidores públicos e obras públicas estão compreendidos pela Ciência da Administração (Public Administration). Confira-se em Schwartz, p. 2.

11 "A governmental body charged with administering and implementing particular legislation. [...] The term 'agency' includes any department, independent establishment, commission, administration, authority, board or bureau of the United States or any corporation in which the United States has a proprietary interest, unless the context shows that such term was intended to be used in a more limited sense." (Black's law dictionary. 6. ed. St. Paul: West Publishing Co., p. 45.) "[...] a department or other unit of government created by legislation to administer the law in a particular area of public concern." (Merriam Webster's dictionary of law. Springfield: Merriam Webster, 1996, p. 19.).

12 A secção 551 do $A P A$ legal destaca que na noção de agência não estão incluídos o Congresso, as cortes, o Governo e outras autoridades excepcionadas. 
Sublinha Schwartz que o APA equipara a agência administrativa ao Poder Executivo. Logo, todo órgão governamental situado fora do Poder Legislativo e do Poder Judiciário seria uma agência administrativa. Adverte, contudo, que o direito administrativo não abrange qualquer agência que possua poderes executivos, mas somente aquelas cuja autoridade atinja direitos e obrigações dos particulares. ${ }^{13}$

Com base no diploma legal citado, Bonfield e Asimow aduzem que as agências administrativas são organismos governamentais, diversos dos Poderes Legislativo e Judiciário, que desempenham funções que lhes foram confiadas pelos legisladores, afetando direitos e obrigações dos administrados. ${ }^{14}$

As agências administrativas (administrative agencies ou somente agencies) podem ser instituídas sob outras denominações, tais como: department, bureau, division, section, commission, board, administration. ${ }^{15}$

Apesar de existir uma norma geral, é importante acentuar a multiplicidade e heterogeneidade das agências norte-americanas, vez que, em princípio, por exemplo, cada agência possui um modelo estrutural próprio, de acordo com a norma que a instituiu.

\subsubsection{Classificações}

As agências administrativas são classificadas sob vários critérios, dentre os quais se destacam aqueles relativos à natureza dos poderes que lhes são conferidos e à independência face ao Poder Executivo.

$\mathrm{O}$ primeiro critério divide as agências em reguladoras (regulatory agencies) e não reguladoras (non regulatory agencies, social welfare agencies ou benefectary agencies).

As agências reguladoras exercem os poderes normativos e decisórios que lhes foram delegados pelo Congresso norte-americano, incidindo sobre as situações jurídicas dos cidadãos com os quais se relacionam. São entes que estabelecem regras para setores econômicos privados, condicionam os direitos e liberdades dos particulares e têm competência para resolver conflitos intersubjetivos (entre a Administração e os cidadãos ou entre cidadãos), embora a participação da Administração não produza qualquer efeito modificativo. A Interstate Commerce Commission a a $\mathrm{Fe}$ deral Trade Commission são agências reguladoras.

13 Schwartz, p. 4. Confira-se também em Lorch (Lorch, Robert S. Democratic process and administrative law. Detroit: Wayne State University Press, 1980, p. 59.)

14 "Administrative agencies are governmental bodies other than the legislature and the courts that affect the rights or duties of individuals or entities. They typically perform missions entrusted to them by statutes that authorize them to take certain kinds of actions for specified purposes. In short, agencies administer or execute law. All levels of government, federal, state, and local, have administrative agencies." (Bonfield e Asimow, p. 1.)

15 Observa Ángel Manuel Moreno Molina que há uma heterogeneidade de nomenclatura, bem como existem diversos conceitos legais de agência, para fins de aplicação de cada legislação específica. Além do "Administrative Procedure Act", o autor reporta-se ao "Freedom of Information Act" (de 1974) e ao "Paperwork Reduction Act" (de 1980), por exemplo. (La administración por agencias en los Estados Unidos de America. Madrid: Marcial Pons, [s.d.], p. 29 e ss.). 
Agências não reguladoras desempenham funções relativas a prestações de serviços de assistência social dos indivíduos (atribuições típicas do Estado do bem-estar), como a proteção dos trabalhadores ou o pagamento de pensões. Suas atividades se reduzem ao reconhecimento de benefícios, no intuito de promover o bem-estar econômico e social. ${ }^{16}$ São exemplos o Department of Labor e a Social Security Administration. ${ }^{17}$

Aplicam-se para as agências reguladoras e não reguladoras as mesmas regras de comportamento e procedimentos administrativos previstos no $A P A$.

As agências podem ainda ser classificadas como independentes (independent regulatory agencies ou commissions) ou executivas (executive agencies), dependendo da previsão ou não de limites para a destituição dos diretores da agência por parte do chefe do poder executivo. ${ }^{18}$

As agências independentes possuem uma autonomia estrutural (orgânica) em relação ao Poder Executivo, porque a destituição de diretores por parte do Presidente dos Estados Unidos se condiciona à decisão do Congresso e somente será admissível se concorrerem causas previstas na norma de criação da agência. Embora os diretores das agências independentes sejam indicados pelo Presidente dos Estados Unidos, com a aprovação do Senado Federal, eles somente poderão ser destituídos com justa causa, consistente em ação danosa ou ilegal ou em omissão. ${ }^{19}$ Ou seja: razões políticas não são suficientes para acarretar a remoção de diretor de agência administrativa independente. Não possuindo cargos vinculados à vontade do Chefe do Poder Executivo, os diretores detêm estabilidade e uma maior liberdade de atuação.

16 " $[\ldots]$ vested with the authority to dispense benefits for promoting social and economic welfare, such as pensions, disability and welfare grants, and government insurance." (Schwartz, p. 5.)

17 O primeiro, por exemplo, criado em 1913, para proteção do trabalhador e fortalecimento de seus direitos, visando a aprimorar as condições de trabalho, é responsável por inúmeros programas destinados ao bem-estar do trabalhador, tais como segurança do trabalho, pagamento de seguro desemprego e oportunidades de formação profissional. Cf. em Sisung, Kelle (Ed.) Federal agencies profiles for students. Detroit: Gale, 1999, p. 814.

18 Embora nem todos os autores adotem o mesmo critério para esta classificação, observa Moreno Molina que a maioria parte dos limites previstos para a destituição dos diretores para qualificar as agências como independentes ou executivas. (Moreno Molina, p. 86.) Frise-se que a classificação concerne unicamente à estabilidade dos diretores das agências em seus cargos e à forma de destituição dos mesmos. $O$ fato de uma agência ser denominada independente não significa que seja funcionalmente independente de outras instituições ou que não se submeta a formas de controle externo. É o que leciona Lawson. (Lawson, p. 8.) Warren destaca que parte da doutrina divide as agências em três grupos: 1) agências reguladoras independentes, 2) agências reguladoras quase-independentes e 3) departamentos executivos. A diferença entre as independentes e as quase-independentes residiria no fato de que enquanto estas estão de certo modo vinculadas a algum órgão governamental, aquelas estão situadas fora da estrutura organizacional do Poder Executivo. Esta classificação não pode ser aceita, pois adota critérios diversos para estabelecer as características das três espécies de agências. (Warren, p. 28.)

19 O direito norte-americano aluda a malfeasance, misfeasance ou nonfeasance. 
Ressalte-se, ainda que de passagem, que outros fatores contribuem para garantir a independência das agências, como a fixação de termos para o exercício de direção, previsão de causas de incompatibilidade para o exercício de tal função, a designação de órgãos colegiados de direção etc. ${ }^{20}$

As agências independentes também estão sujeitas à intervenção do Presidente no que se refere à coordenação das políticas públicas, bem como a outras formas de controle por parte dos Poderes Legislativo, Executivo e Judiciário. Dessa maneira o que se estaria buscando com a independência seria evitar interferências externas nas agências.

Alguns doutrinadores norte-americanos criticam a independência das agências frente ao controle político, pois entendem que as agências independentes se transformaram em um quarto poder estatal, o que dificultaria a adoção de políticas públicas de forma homogênea. ${ }^{21}$

Além das agências reguladoras mencionadas, a Securities and Exchange Commission e a Federal Communications Commission são algumas das agências federais independentes.

As agências executivas normalmente são menos independentes que as anteriores, por se submeterem a uma supervisão presidencial mais intensa. ${ }^{22} \mathrm{O}$ chefe do poder executivo possui poder absoluto de remoção dos ocupantes de cargos de direção das agências executivas, sem necessidade de aprovação do ato por parte do Congresso.

Dentre as agências executivas pode-se citar os Department of Health and Human Services e Department of Defense.

\subsection{Evolução do Direito Administrativo norte-americano}

Algumas considerações acerca da evolução do direito administrativo norte-americano são imprescindíveis, para que se proporcione uma melhor compreensão do desenvolvimento das agências administrativas.

É clássica a divisão do direito administrativo norte-americano em cinco fases:

1) $1875-1930$;

2) $1930-1945$;

3) $1945-1965$;

4) $1965-1985$;

5) 1985 em diante

20 Para um estudo relativo à independência dos entes reguladores, confira-se em Chirillo, Eduardo J. Rodriguez. Privatización de la empresa pública y' post privatización. Buenos Aires: AbeledoPerrot, 1995.

21 Sobre o tema, confira-se as lições de Warren. (Warren, p. 29.)

22 Preieciona Eloísa Carbonell Porras que a noção de agência executiva compreende estruturas organizativas variadas, pois inclui os diferentes departamentos ministeriais, os serviços ou escritórios que os integram, além de agências não inseridas estruturalmente em nenhum departamento. (Carbonell Porras, Eloisa: Muga Muñoz, José Luis. Agencias y procedimiento administrativo en Estados Unidos de América. Madrid: Marcial Pons, 1996, p. 51.) 
Como ocorreu com outros ramos do direito norte-americano, o direito administrativo se originou com as decisões dos tribunais ingleses e as medidas estabelecidas para controlar a crescente variedade de funções administrativas.

Enquanto perdurou a política do liberalismo econômico e a separação absoluta entre as esferas pública e privada, o Estado não interferia na atuação dos particulares. Na segunda metade do século XIX, no entanto, há um crescimento da regulação administrativa da atividade econômica privada, inicialmente na esfera estadual. ${ }^{23}$ Em 1887 foi instituída a primeira agência reguladora federal, a Interstate Commerce Commision, e em 1914 surgiu a Federal Trade Commission.

Durante esta primeira etapa do desenvolvimento do direito administrativo norte-americano os tribunais entendiam que a atuação das agências administrativas poderia ser revista e suas decisões reformadas, analisando não somente a legalidade, mas igualmente o mérito dos atos administrativos. ${ }^{24}$

Quatro elementos caracterizam o modelo tradicional: (1) a imposição de sanções pela Administração aos particulares deveria ser autorizada pelo Poder Legislativo, através de regras que controlassem a atuação das agências administrativas; (2) os procedimentos decisórios adotados pelas agências deveriam se pautar pelas diretivas legislativas; (3) possibilidade de revisão jurisdicional da atividade das agências, a fim de assegurar a utilização pelas agências de procedimentos precisos e imparciais, conforme às diretivas impostas pelos legisladores; (4) o processo decisório utilizado pelas agências deveria facilitar o exercício da revisão judicial. ${ }^{25}$

Em virtude da crise econômica e do descrédito no mercado livre, impôs-se uma intervenção maior do Estado nas atividades econômicas privadas. Assim, durante o governo de Franklin D. Roosevelt foi implementada a política do New Deal.

Nesta fase do direito administrativo norte-americano (entre 1930 e 1945), as agências administrativas passaram a ser uma característica relevante do governo norte-americano. ${ }^{26}$ Elas detinham a posição de um "quarto poder", ao lado dos Poderes Legislativo, Executivo e Judiciário, em razão da combinação das funções que exerciam (executiva, normativa e decisória).

O período de maturação do modelo tradicional de direito administrativo (19451965) foi marcado pela imposição de requisitos procedimentais às agências.

23 Através da fixação de tarifas para o transporte ferroviário. por exemplo.

24 A respeito desse tópico, são valiosas as lições de Breyer e Stewart. (Breyer e Stewart, p. 18 e 19.)

25 Breyer e Stewart, p. 18 e 19.

26 Betancor Rodríguez destaca dois fatores que influenciaram a proliferação de agências independentes durante o New Deal: 1) necessidade de independência das agências face à natureza das funções que lhes foram outorgadas: 2) em decorrência de sua desconfiança no Presidente, o Congresso procedeu à criação de autoridades que desenvolvessem funções administrativas sem estarem submetidas ao controle do Presidente, evitando assim que o Poder Executivo acumulasse prerrogativas em demasia e colocasse em risco o equilíbrio dos poderes. (Betancor Rodriguez. Andrés. Las administraciones independientes. Madrid: Tecnos, 1994, p.32 e 33.) Entre as agências do New Deal se incluem: Federal Home Loan Bank Board. Securities and Exchange Commission. Social Security Board, Commodity Exchange Commission, dentre outras. 
Face às críticas à injustiça dos procedimentos administrativos utilizados pelas agências, em 1940 o Congresso norte-americano aprovou uma lei - Walter Logan bill - prevendo modelos procedimentais para as agências federais e determinando uma maior abrangência das hipóteses de revisão judicial de suas decisões.

Em 1946, foi editado o Federal Administrative Procedure Act (APA) - lei de procedimentos administrativos. Acompanhando as previsões federais, os Estados também promulgaram leis sobre procedimento administrativo.

A Lei de Procedimentos Administrativos estabeleceu certas formalidades para as atividades das agências e a obrigatoriedade de respeito a determinados princípios, tais como a previsão de revisão judicial e a publicidade dos atos administrativos.

Embora os tribunais concedessem às agências uma grande margem de liberdade para a formulação e implementação de políticas públicas, houve uma intensificação na apreciação dos fatos por parte do Poder Judiciário.

Entre 1965 e 1985 aumentou a desconfiança em relação aos procedimentos administrativos e à revisão judicial dos mesmos. Demonstrou-se a necessidade de controles mais abrangentes e rígidos sobre a atuação das agências.

Os tribunais responderam a tais demandas, estendendo o direito de participar dos processos decisórios das agências e procurar proteção judicial a categorias antes não protegidas (estudantes, beneficiários do sistema de previdência social etc.). ${ }^{27}$

Esta etapa se caracteriza pela existência de entendimentos antagônicos. Ao mesmo tempo em que surgiram propostas para aumentar a participação dos particulares nos procedimentos administrativos, sugeria-se a desregulação de algumas áreas. ${ }^{28}$

Desde 1985 o direito administrativo norte-americano vive um momento denominado de retrocesso ou consolidação.

Discute-se a eficiência das agências e o custo-beneficio da regulação. Por outro lado, diversas medidas de desregulação foram tomadas. ${ }^{29}$

Quanto à posição dos tribunais, Breyer e Stewart destacam as seguintes medidas adotadas pela Suprema Corte norte-americana: (1) concedeu às agências liberdade

27 Breyer e Stewart, p. 27.

28 Desregulação ou desregulamentação (para alguns autores os termos são utilizados como sinônimos) consiste na alteração qualitativa e quantitativa da regulação. Trata-se do abandono total ou parcial do controle público sobre a atividade privada, a fim de potencializar a livre concorrência. Implica abolição, redução dos objetivos e intensidade, bem como modificação dos sistemas de controle. Exemplos das medidas adotadas neste intuito são a liberação de preços e a derrogação de privilégios. Assim como a regulação, a desregulamentação está associada atualmente a um novo modelo de Estado, em que se busca a retirada do Estado (retreat of the State) do campo econômico. As razōes para esta forma de liberalização dos mercados pode decorrer, dentre outros fatores, da inabilidade dos reguladores para efetuar um controle eficiente. Para uma melhor análise do tema, confira-se em De La Siema Bilbao, Maria Nieves. (La privatización en España: fundamentos constitucionales y comunitarios. Pamplona: Aranzadi, 1995, p. 39 e ss.)

29 S.Wann aponta o Air Passenger Deregulation Act, de 1978, como uma das medidas de desregulação mais amplas efetuadas nos Estados Unidos. (SWANN, Dennis. The retreat of the state: (Deregulation and privatization in the UK and US). [S.1.] The University of Michigan Press, 1991, p. 170.) 
considerável em relação à revisão judicial, quando decidem não adotar determinado comportamento; (2) limitou as hipóteses em que os tribunais podem infligir às agências novas exigências procedimentais; (3) impôs aos tribunais que atentassem para as diversas interpretações das normas formuladas pelas agências. ${ }^{30}$

\section{O poder normativo das agências reguladoras norte-americanas}

\subsection{Delegação de poderes}

As agências reguladoras norte-americanas possuem independência em relação ao Poder Executivo, não estando submetidas a controle hierárquico. São autorizadas a elaborar algumas regras jurídicas e aplicá-las a casos concretos e detêm poderes para fiscalizar, investigar, punir e decidir controvérsias. Possuem poderes amplos para emitir normas e decidir litígios, denominados de poderes "quase-legislative" e "quase judicial".

As agências são criadas pelo Poder Legislativo, que lhes outorga os poderes anteriormente nominados. A doutrina e jurisprudência norte-americanas sempre questionaram se a combinação de funções executiva, legislativa e jurisdicional pelas agências não violaria o princípio constitucional da separação de poderes. ${ }^{31}$ Indaga-se se a delegação de poderes pelo Legislativo e Judiciário seria constitucional. ${ }^{32}$

A Constituição norte-americana distingue os poderes legislativo, ${ }^{33}$ executivo ${ }^{34}$ e judiciário ${ }^{35}$, mas não faz menção às agências administrativas. Além disso, os constituintes não previram a possibilidade de delegação de poderes legislativos. A doutrina confirma, no entanto, que esta delegação sempre ocorreu.

30 Breyer e Stewart, p. 30.

31 Lorch assinala que, embora a Constituição norte-americana não utilize o termo separação de poderes, esta idéia está implícita quando, em seus artigos $1^{\circ}, 2^{\circ} \mathrm{e} 3^{\circ}$. que prevêem que cada um dos três Poderes detém controle exclusivo sobre sua própria gama de funções. (Lorch, p. 75.)

32 The Anglo-American separation of powers principle not only distinguishes between those who make general laws and those who implement and apply them. but also reserves a special role for independent judiciary in this process. [...] These traditional principles and practices have been threatened by the creation of administrative agencies that combine lawmaking, adjudicative, and executive functions." (Breyer e Stewart, p. 34.)

33 " all legislative powers herein granted shall be vested in a Congress of the United States, which shall consist of a Senate and House of Representatives." (Secção 1, do artigo $1^{\circ}$, da Constituição norte-americana). "the Congress shall have power $[. .$.$] to make all laws which shall be necessary$ and proper" (Secção 8 do mesmo artigo).

34 "The executive power shall be vested in a President of the United States of America [...]." (Seç̧ão 1 do artigo $2^{\circ}$.)

35 "The judicial power of the United States shall be vested in one supreme Court and in such inferior Courts as the Congress shall form time to time ordain and establish". (Seção 1 do artigo $3^{\circ}$.) 
WARREN observa que, apesar de a Constituição prescrever sobre a separação dos poderes, tão logo se tornaram congressistas os constituintes passaram a delegar parte dos poderes que lhe haviam sido conferidos, através de autorizações ao Presidente para regular pensões dos militares ou da delegação de poderes para o Poder Judiciário, a fim de que se organizasse, por exemplo. ${ }^{36}$

Inicialmente os tribunais norte-americanos entenderam que o poder legislativo, delegado ao Congresso pela Constituição, não poderia ser delegado. Consagrou-se, assim, o princípio da não delegação (non-delegatio), segundo o qual qualquer delegação de poder normativo pelo Poder Legislativo seria inconstitucional. ${ }^{37}$

Ao que tudo indica, a doutrina da não delegação não perdurou em virtude de razões práticas. Além da necessidade que tinham as agências em editar normas, para implementar as políticas públicas, o Poder Legislativo não possuía condições para legislar sobre todas as matérias relativas às agências, precipuamente face ao volume e à especificidade das mesmas. ${ }^{38}$

Aos poucos o Poder Judiciário foi admitindo a delegação de poderes legislativos e também foi ampliando as hipóteses em que era permitida.

A partir da decisão prolatada no caso United States v. Curtiss-Wright Export Co., de 1936, os tribunais opinaram em favor da delegação de poderes por parte do Congresso norte-americano, desde que este fixasse "standards" com significado determinável (meaningful standards) para guiar os administradores. ${ }^{39}$ Trata-se da teoria denominada de "intelligible principle".

Para esta doutrina, destaca Carbonell Porras, admitem-se amplas cessões de poder por parte do Congresso sempre que ele tenha predeterminado o alcance do poder que transfere, assinalando uma diretriz legislativa suficientemente clara e concreta, para que a agência atue segundo a vontade do legislador, com a mínima discricionariedade. ${ }^{40}$

36 Warren, p. 88. Kerwin salienta que o Congresso também delegou ao Presidente poder para legislar sobre o comércio com as tribos indígenas. (Kerwin. Cornelius. Rulemaking: (How government agencies write law and make policy). 2.ed. Washington: Congressional Quarterly Inc., 1999, p. 7.)

37 No sentido da não delegação de poderes foram proferidas as decisões nos casos Cincinnati, W.\& Z.P. Co. v Commissioner, 1 Ohio St. 77, 88: Field ․ Clark, 143 U.S. 649 (1892) e United State v Shreveport Grain and Elevator Co., 287 U.S. 77 (1932), citados por Warren. (Warren, p. 89.)

38 Cf. Carbonell Porras e Muga Munoz, p. 27. Lorch ensina que cada vez mais poderes legislativos e jurisdicionais foram sendo delegados às agências, face à crescente atuação do governo na supervisão das áreas econômica e social e porque os legisladores não possuem tempo, conhecimento ou habilidade para conceber regras para muitas áreas sob a atuação das agências. (Lorch, p. 79.)

39 Os autores mencionam os julgamentos de Sunshine Anthracite Coal Co. v. Adkins, 310 U.S. 381 (1940) SEC v. Chenery Corp., 332 U.S. 194 (1947) e United States v. Southwestern Cable Co., 392 U.S. 157 (1968). Neste último feito, a Suprema Corte determinou os "standards" a serem seguidos, asseverando que a agência deveria administrar de forma consistente com o direito, consoante demandado pela conveniência pública, seu objetivo ou necessidade. (Cf. Warren, p. 90.) 40 A autora destaca que o princípio evoluiu dos denominados meaningful standards, que permitem predeterminação pela lei do poder da agência. ao estabelecer princípios ou diretrizes suficientes e claros, para os meaningless standards, que não possibilitam essa limitação dos poderes administrativos. (Carbonell Porras e Muga Muñoz. p. 26.) 
SCHWARTZ frisa que o tema da delegação de poderes legislativos passou da proibição teórica absoluta para a regra contra qualquer delegação irrestrita, ${ }^{41}$ sendo admitida a delegação, desde que limitada por "standards". Há necessidade de verificar-se a constitucionalidade da lei delegante e se a concreta atuação da agência está respaldada por lei, ou seja, se está dentro dos limites fixados pelo legislador.

Quanto à delegação de poderes jurisdicionais, o debate nunca foi intenso. A polêmica maior sempre foi acerca da delegação de poder normativo, pois questiona o princípio da representatividade e responsabilidade democrática, mas também porque os atos legislativos têm maior impacto sobre a sociedade do que os atos judiciais, por serem macroorientados.

Ademais, a delegação de poder juridicional seria em princípio menos ameaçadora em relação ao princípio da separação de poderes, visto que as decisões emitidas pelas agências se submetem a maior controle por parte do Judiciário do que suas regras. $^{42}$

\subsection{A atividade normativa das agências reguladoras}

\subsubsection{Noção de regulamento}

Regulamento (rule ou regulation) é norma elaborada por uma agência administrativa, destinada a regular operações internas da agência ou a auxiliar na implementação das políticas públicas que lhe foram designadas pelos legisladores.

Para o Administrative Procedure Act, regulamento significa "o conjunto ou parte de uma declaração administrativa de aplicabilidade geral ou particular e eficácia futura, dirigida a implementar, interpretar ou estabelecer Direito ou princípios gerais de atuação, ou a descrever a organização, o procedimento ou a prática de uma agência". 43, 44

41 Schwartz, p.44.

42 Schwartz, p. 86.

43 Section 551, (4): " 'Rule' means the whole or part of an agency statement of general or particular applicability and future effect designed to implement, interpret, or prescribe law or policy or describing the organization, procedure, or practice requirements of an agency and includes the approval or prescription for the future of rates, wages, corporate or financial structures or reorganizations thereof, prices, facilities, appliances, services or allowances therefore or of valuations, costs, or accounting, or practices bearing on any of the foregoing." "'Regulation' or 'rule' means an agency statement of general applicability and future effect, which the agency intends to have the force and effect of law, that is designed to implement, interpret, or prescribe law or policy or to describe the procedure or practice requirements of an agency". (Executive Order $12866 \S 3$ (d), que complementa o $A P A$ )

44 Para uma análise pormenorizada dos elementos presentes na definição apresentada pelo dispositivo legal, é oportuno conferir os ensinamentos de Kerwin. (Kerwin, p. 2 a 6.) 
Considera-se que um regulamento "implementa", nas hipóteses em que o Direito ou os princípios gerais de atuação (política pública) tenham sido amplamente desenvolvidos em lei aprovada pelo Congresso, ordem executiva do Presidente ou em decisão judicial. Nesses casos os regulamentos se atêm a orientar os administradores e ao público.

Há interpretação por parte das normas quando, embora o Direito e os princípio gerais de atuação tenham sido bem fixados, surgem circunstâncias imprevistas ou alterações que demandam esclarecimentos. Assim, por exemplo, certos termos de lei, inicialmente claros e precisos, podem necessitar adaptação quando novas práticas comerciais ou tecnológicas são realizadas. ${ }^{45}$

Se o Congresso, ao estabelecer os objetivos do Direito e princípios gerais de atuação nas leis, prever poucas orientações acerca de como devem ser implementados ou como devem ser alcançados, cabe aos regulamentos das agências apresentar os esclarecimentos necessários. Isto ocorre nos casos em que a lei deixa para a agência a definição de termos amplos, tais como "saudável" ou "interesse público".

A definição apresentada pelo APA enfatiza que os regulamentos possuem efeito futuro. Em princípio não são admissíveis regulamentos com efeitos retroativos, pois os regulamentos têm sempre o escopo de modelar situações futuras. $O$ elemento "efeito futuro" é crucial na definição, visto que demonstra o contraste entre as funções normativa e decisória das agências. Normalmente os regulamentos (rules) estabelecem normas ou políticas para o futuro, enquanto as decisões das agências (orders) geralmente determinam direitos individuais, baseando-se em fatos passados ou com efeitos retroativos.

O diploma legal também alude ao âmbito de aplicação dos regulamentos: geral ou particular. Podem afetar pessoas ou atividades nas mais variadas circunstâncias: um único particular, grupos, segmentos da comunidade, unidades do governo etc. Outra distinção entre os regulamentos e as decisões das agências decorre do critério geral ou particular de aplicação. Os regulamentos de regra são abstratos e afetam ou podem afetar uma pluralidade de indivíduos. Já os atos decisórios das agências são particulares, incidindo sobre pessoas determinadas.

\subsubsection{Classes de regulamentos}

No direito norte-americano se distinguem três categorias principais de regulamentos: 1) procedimentais - procedural rules -, 2) substantivos ou legislativos legislative rules - e 3) interpretativos - interpretative rules. ${ }^{46}$

45 Este exemplo é citado por Kerwin (Kerwin, p. 5.)

46 Carbonell Porras acrescenta uma quarta espécie de regulamentos, as declarações gerais de política - general statement of policy. Elas consistem em comunicação da agência ao público sobre a maneira como se propõe a exercer seu poder discricionário. São declarações gerais das intenções da agência no desenvolvimento de sua política, por exemplo. Não têm caráter obrigatório. (Carbonell Porras e Muga Muñoz, p. 64) 
Regulamentos procedimentais e organizativos referem-se à organização da agência, suas regras de funcionamento (procedimentos) e suas práticas, tendo relevância meramente interna.$^{47}$ Não dependem de delegação expressa de poder normativo por parte do Poder Legislativo, possuindo as agências poder implícito para fixar as normas acerca de seu funcionamento. ${ }^{48}$

Os regulamentos legislativos são aqueles aprovados por uma agência, consoante autorização legislativa e almejando implementar uma lei. ${ }^{49}$ Criam direitos e deveres que não existiam antes de sua aprovação, modificando a situação jurídica dos cidadãos. Têm força de lei, vinculando a agência, os particulares e os tribunais e devem ser editados em consonância com os procedimentos determinados pelo APA.

Interpretativos são regulamentos ou acordos aprovados por uma agência, no intuito de comunicar ao público seu entendimento em relação a leis e regulamentos de sua competência. Explicam ou esclarecem o sentido de determinada lei e dos regulamentos substantivos da própria agência, precisando como se aplicam. ${ }^{50}$ Não são lei em sentido material, não possuindo efeito vinculante.

Se o regulamento somente estatui como a agência interpreta a lei, trata-se de regulamento interpretativo. No entanto, se pretende criar nova lei, direitos ou obrigações, está-se diante de regulamento substantivo. A distinção é importante para determinar as formalidades necessárias para a criação das regras, bem como qual o efeito legal conferido. As regras interpretativas, embora demandem publicação, não se submetem aos procedimentos normativos previstos no APA. Por outro lado, em princípio, somente os regulamentos substantivos têm força de lei ${ }^{51}$.

\subsubsection{Procedimentos normativos}

Não sendo escopo deste trabalho discorrer acerca dos procedimentos normativos, abordaremos somente suas características principais.

47 Adverte Kerwin que, embora os regulamentos organizativos sejam vistos usualmente como meros expedientes burocráticos, relativos à organização interna das agências, eles tratam de matérias importantes para os particulares. Assim, dentre outras funções, podem informar o público como participar dos procedimentos das agências, inclusive do processo normativo. (Kerwin, p, 23.)

48 Segundo o $A P A$, as agências são obrigadas a elaborar e publicar regulamentos procedimentais, conforme previsão na seção 552 (a) (1) (C).

49 "A substantive rule or 'legislative rule' is one 'affecting individual rights and obligations'; it is the administrative equivalent of a statute, compelling compliance with its terms on the part of those within the agency ambit. Substantive rules are issued pursuant to statutory authority and implement the statute; they create law just as the statute itself does, by changing existing rights and obligations." (Schwartz, p. 181.)

50 "An interpretative rule is an expression by the agency of its own construction of a statute or rule. Interpretative rule serve an advisory function: they express an agency's intended course of action or its view of the meaning of a statute or regulation; they are statements issued to advise the public of the agency's construction of the law it administers." (Schwartz, p. 181.)

51 "Nonlegislative rules, often called interpretative rules or statements of policy, are agency rules that do not have the force of law because they are not based upon any delegated authority to issue such rules." (Bonfield e Asimow, p. 249.) 
Afirma Schwartz que o processo normativo das agências ou rulemaking é o equivalente administrativo do processo legislativo para aprovação de uma lei. ${ }^{52} \mathrm{De}$ acordo com a secção 551 (5) do $A P A$, trata-se de processo de formulação, emenda ou rejeição de um regulamento. ${ }^{53}$

O APA prevê a estrutura básica dos procedimentos normativos a serem seguidos pelas agências federais norte-americanas. Nada impede, todavia, que as disposições sobre procedimentos possam ser complementadas e até modificadas por legislação específica.

A Lei de Procedimentos Administrativos admite três modalidades de procedimentos normativos: formal (trial-like hearing rule-making), informal (notice and comment rule-making) e negociado (new rule-making approach ou negotiated rulemaking).

O modelo informal está regulado na seção 553 do APA. É o procedimento usualmente adotado, que garante a comunicação pública da intenção de aprovar um regulamento, um trâmite de participação dos cidadãos e a publicação do texto definitivo. As exigências básicas deste procedimento consistem no dever de informação a respeito da intenção de elaborar regulamento e na oportunidade para comentário garantida aos particulares. Por esta razão referido procedimento também é conhecido pela denominação notice-and-comment rulemaking.

Seu propósito é de, através da participação popular, fornecer mais subsídios para as agências desempenharem suas funções. Não se aplica a algumas matérias expressamente excluídas em lei ${ }^{54}$ nem a determinados tipos de regulamentos. Unicamente os regulamentos substantivos precisam ser aprovados por um concreto procedimento normativo, formal ou informal, segundo determinar a lei referente à agência. Estão dispensados desta exigência os regulamentos procedimentais, interpretativos e as declarações gerais de política. É o que esclarece a seção 553 (A) do $A P A$.

O procedimento formal deve ser adotado quando a lei o exigir. ${ }^{55} \mathrm{Tem}$ em comum com o informal as fases de publicação da proposta e da norma final. A diferença

52 Schwartz, p. 189.

53 "Section 551 (5): 'Rule making' means agency process for the formulating, amending, or repealing a rule."

54 “§ 553. Rulemaking

(a) This section applies, accordingly to the provisions thereof, except to the extent that there is involved

(1) a military or foreign affairs function of the United States; or

(2) a matter relating to agency management or personnel or to public property, loans, grants, benefits, or comracts."

$55 \$ 553$ (c): “...When rules are required by statute to be made on the record after opportunity for an agency hearing, sections 556 and 557 of this title apply instead of this section". O Food. Drug. and Cosmetic Act, de 1938, exige a adoção de procedimento normativo formal por parte da Food and Drug Administration, para a elaboração de regulamentos. É imperioso salientar que poucas normas requerem a utilização deste procedimento. (Cf. Warren, p. 253.) 
fundamental reside na participação dos cidadãos, nos direitos que lhes são reconhecidos e nos critérios que a agência deve considerar para a aprovação do regulamento. ${ }^{56}$

O procedimento formal se assemelha ao procedimento decisório formal ("adjudication"), previsto no APA. O APA impõe a adoção de grande parte das formalidades procedimentais requeridas para o processo decisório. São necessárias a celebração de uma audiência contraditória e formal na qual às partes é facultado apresentar alegações e provas, além da formalização de um expediente administrativo que fundamente a redação final do regulamento.

Em 1990 o Congresso norte-americano aprovou o Negotiated Rulemaking Act, reforma do APA (seções 561-583), que possibilitou a elaboração de regulamentos por meio de negociação entre as agências e representantes de várias organizações. ${ }^{57}$ A finalidade principal da medida é permitir maior participação dos interessados no processo normativo e proporcionar uma consequiente maior aceitação dos regulamentos expedidos pelas agências.

Além dos regulamentos que dependem da tramitação de um procedimento normativo formal ou informal, há aqueles que não estão sujeitos a requisitos procedimentais e outros que se submetem a uma pluralidade de procedimentos hibridos, previstos nas normas que regulamentam cada agência.

Embora não sejam formais, os procedimentos híbridos incorporam requisitos suplementares para o trâmite informal, a fim de restringir a discricionariedade da agência na adoção de regulamentos. ${ }^{58}$ Normalmente se orientam a potencializar a participação dos cidadãos e se originam por vontade da própria agência ou por imposição do Congresso. ${ }^{59}$

O Federal Trade Commission Improvement Act, de 1974, por exemplo, concede à Federal Trade Commission poder normativo que pode ser exercido além dos requisitos do procedimento de notice and comment.

56 " [...] normally include the taking of evidence by an administrative law judge or other hearing officer through adversary trial-type proceedings, an initial or recommended decision by that officer based on the evidence presented, followed by opportunity for an appeal procedure before the agency heads on the basis of the record compiled by the hearing officer." (Breyer e Stewart, p. 526.)

57 "More recently some agencies have tried to develop rules through a process of negotiation. The agency selects a facilitator to convene meetings of interested parties. They will meet with staff to propose rules, to discuss their own proposals, and to try to come up with a final, agreed-upon rule. including the rule's specific language. The agency promises to adopt the consensus proposal. at least, if subsequent notice and comment do not reveal serious flaws." (Breyer e Stewart, p. 609.) 58 "The 'common law' development by reviewing courts of hybrid rulemaking procedures has been emulated by Congress. Several of the regulatory statutes enacted by Congress during the $1970 \mathrm{~s}$ explicitly grant rulemaking power to administrators, but hedge its exercise with specific procedural requirements that go beyond $\$ 553$ notice and comment procedures without requiring oral trial-type hearings in every case." [...] "Other rulemaking formalities beyond notice and opportunity for comment required by statutes include consultation with specific officials or organizations; creation of and consultation with advisory committees, and shared responsibility with other agencies for promulgating rules." (Breyer e Stewart, p. 579 e 580.)

59 Schwartz limita a utilização de procedimentos híbridos para as hipóteses em que haja imposição legal. (Schwartz, p. 204.) 
O poder das agências para legislar em geral decorre de delegação efetuada pelo Poder Legislativo e não deve ultrapassar a autoridade que lhe foi concedida. A lei é a fonte do poder normativo da agência, bem como seu limite. Se uma agência agir além de seus poderes (ultra vires), sua ação não será válida.

Para que um regulamento seja válido não é permitido que a agência exceda os poderes que lhe foram conferidos (critério da doutrina ultra vires). É preciso, também, que o regulamento não seja arbitrário ou desarrazoado, ou seja, deve ser consistente com a lei e razoavelmente vinculado aos objetivos fixados pela legislação que delegou os poderes normativos à agência.

\subsubsection{Considerações acerca da atividade normativa}

Acompanhando os ensinamentos de Kerwin, as principais características dos procedimentos normativos desenvolvidos pelas agências norte-americana podem ser regrupadas em três princípios, que visam a conferir maior legitimidade à atuação destes entes: princípios da informação, da participação e da responsabilidade ${ }^{60}$ Sobre eles passamos a tecer alguns comentários.

\subsubsection{Princípio da informação}

O princípio da informação comporta duas faces distintas. A primeira relacionada com as informações que as agências obtêm, desenvolvem e consideram no decorrer do processo normativo. A segunda concerne ao que as agências estão obrigadas a divulgar ao público, durante e após a elaboração de um regulamento.

As agências precisam de informações de diversas ordens para realizarem seu trabalho. Algumas leis esclarecem o tipo de dados que as agências considerarão para a elaboração de regulamentos. Assim, por exemplo, o Occupational Safety and Health Act afirma que a Occupational Safety and Health Administration deve basear seu trabalho em pesquisas, demonstrações, experimentos e outras informações que forem necessárias. ${ }^{61}$

$\mathrm{O}$ aspecto mais relevante do princípio da informação, no entanto, vincula-se à divulgação efetuada pelas agências, em conexão com outro princípio democrático o da participação dos cidadãos no processo de elaboração dos regulamentos. É impossível separar os princípios da informação e da participação, porque a participação efetiva dependerá sempre de acesso a informações pertinentes. Aliás, o objetivo da divulgação seria incentivar a transparência e a participação democrática no processo de elaboração de normas.

Adotada uma proposta de regulamento, é necessário difundi-la no Federal Register, ${ }^{62}$ publicação governamental diária, desta forma permitindo a participação

60 Kerwin, p. 53.

61 Kerwin, p. 58-59.

62 É o que exige a Secção 553 (b), do APA, verbis: "General notice of proposed rule making shall be published in the Federal Register, unless persons subject thereto are named and either personally 
dos cidadãos interessados, aqueles que potencialmente sofrerão com as consequiências do regulamento a ser editado.

A publicação do texto definitivo do regulamento no Federal Register também é indispensável, ${ }^{63}$ pois uma vez que as regras produzirão efeitos de lei (ressalvadas as hipóteses já mencionadas), seu conteúdo precisa ser acessível aos particulares afetados. O regulamento é sempre precedido de uma declaração geral e concisa de seu fundamento e propósito, a fim de se demonstrar que a agência deu adequada resposta aos comentários dos particulares.

O APA determina que a publicação de um regulamento seja efetuada no mínimo 30 dias antes de sua entrada em vigor ${ }^{64}$ Esta previsão, no entanto, comporta exceção, fundada em causa justa, a ser explicitada junto com o texto do regulamento.

Há igualmente uma variedade de regras criando direitos para os particulares acessarem informações referentes à atividade das agências. O Federal Records Act define as espécies de arquivos que as agências estão compelidas a criar e manter. $O$ Freedom of Information Act especifica em quais circunstâncias os membros do público podem inspecionar tais arquivos. O Freedom of Information Act especificamente determina a apresentação de qualquer documento sob poder de agências federais, uma vez feita a demanda por qualquer particular, salvo algumas circunstâncias relativas à segurança pública, informações comerciais ou financeiras confidenciais previstas, por exemplo, no Trade Secrets Act.

A permissão para os indivíduos obterem informações que o governo guarde sobre eles está garantida pelo Privacy Act. O Government in the Sunshine Act requer que algumas reuniões de agências federais sejam realizadas em sessões abertas ao público (audiências públicas). Estes dispositivos procuram permitir uma maior participação dos particulares e transparência na atuação das agências.

\subsubsection{Princípio da participação}

De maneira geral, a proposta de regulamento é formulada integralmente pela agência, pois o público normalmente não tem ciência da intenção da agência em elaborar regulamentos sobre uma matéria específica ou não lhe é permitido participar,

served otherwise have actual notice thereof in accordance with law." $O A P A$ requer que a "notícia" de proposta contenha alguns dados essenciais, como: 1) declaração do período, local e natureza do processo normativo; 2) referências quanto à autoridade para a qual o regulamento foi proposto; 3 ) os termos da proposta de regulamento ou substância da proposta ou uma descrição dos tópicos em questão. (Secção 553 (b) (1), (2) e (3)) Não se requer que a proposta seja publicada. Basta que a substância da regra seja tornada acessível ou a descrição dos temas abordados. Algumas leis impōem uma publicação mais minuciosa, como é o caso do Federal Trade Commission Act. (Cf. Kerwin. p. 64.)

63 Conforme prevê a Seç̧̃̃o 553 (c) do $A P A$.

64 Este é o teor da Seç̧ão 553 (d) do APA. O dispositivo em seguida arrola algumas hipóteses em que o prazo de 30 dias não é exigido. 
a não ser depois de a agência formalmente iniciar o processo normativo, com a publicação da proposta de regulamento. ${ }^{65}$

É imperioso dar-se oportunidade para que as pessoas interessadas tomem parte ativa no processo legislativo, apresentem informações e sugestões à criação, emenda ou revogação de um regulamento. ${ }^{66}$

Trata-se de uma forma importante para se viabilizar o controle social das atividades desenvolvidas pelas agências reguladoras.

O APA prescreve apenas que seja viabilizada a submissão de material escrito, não exigindo que se realize audiência pública, oral, formal. Exceto os casos em que haja imposição de adoção de procedimento normativo formal. No entanto, estas audiências são utilizadas frequientemente, por decisão das próprias agências.

A não ser que alguma lei requeira de outra forma, a audiência no procedimento normativo é informal, não se assemelhando àquela perante o Poder Judiciário. Em princípio, não existindo leis específicas versando sobre o tema, cabe às agências fixar a forma e extensão da participação pública.

A legitimidade para participar do procedimento normativo das agências é ampla, sendo reconhecida pelos tribunais norte-americanos aos cidadãos cujos interesses sejam afetados, ${ }^{67}$ ainda que incidentalmente, e a suas associações, precipuamente nas áreas da saúde, previdência, meio ambiente e consumo. ${ }^{68}$

Quanto à vinculação da agência em relação aos documentos e comentários remetidos pelos cidadãos, o $A P A$ ordena que a agência considere os aspectos mais relevantes.

A doutrina critica este entendimento, pois isto permitiria que as agências nem sequer apreciassem as manifestações dos particulares. Por esta razão, os tribunais norte-americanos têm exigido que as agências apreciem todas as questões levantadas e elaborem expediente contestando as alegações dos particulares que foram rejeitadas, a constar expressamente no preâmbulo do regulamento.

A participação pública não se restringe a legitimar o processo normativo, sendo igualmente valiosa sua contribuição para a determinação do conteúdo do regulamento. Por isto, houve aumento na concessão de oportunidades para participação pública no processo normativo das agências. O Freedom of Information Act e o Government in the Sunshine Act, citados, exemplificam o fato. Da mesma forma, o Consumer

65 Sobre o tema, confira-se em Bonfield e Asimow, p. 286.

66 "After notice required by this section, the agency shall give interested persons an opportunity to participate in the rule making through submission of written data, views, or arguments with or without opportunity for oral presentation. After consideration of the relevant matter presented. the agency shall incorporate in the rules adopted a concise general statement of their basis and purpose." (Seç̧ão 553 (c) do $A P A$ )

67 Ressalta Schwartz que inicialmente acreditava-se que somente poderia participar do processo normativo a "parte óbvia" (obvious party), ou seja. aquele que é sujeito ou objeto de atuação da agência, cujos direitos e obrigaçōes são diretamente afetados pela atuação dela. Progressivamente. houve alargamento do conceito de parte interessada para abranger igualmente concorrentes e até o público consumidor. (Schwartz, p. 295.)

68 Cf. Carbonell Porras e Muga Muñoz, p.70. 
Product Safety Act e o Medical Derice Amendments to Food. Drug and Cosmeric Acl. autorizando que grupos e organismos não governamentais desenvolvam e apresentem projetos de regulamentos às agências e a emenda ao Clear W'ater Act. de 1977. ampliando para 60 dias o prazo para que sejam apresentados comentários pelo público. ${ }^{\text {h" }}$

No que tange ao acréscimo de participação dos particulares no processo normativo, é preciso assinalar a importância da instituição do procedimento negociado (negotiated rulemaking) em 1990. Segundo o Negotiated Rulemaking A $t$. anunciada a intenção de criar um regulamento. podem as agências reunir-se com os setores interessados para alcançar um texto negociado. seguindo-se o rito específico.

Parece óbvio que a participação se restringe a uma parcela pequena da população e abrange principalmente grupos de indivíduos que possuam capital. conhecimentos técnicos. tempo. Não se pode contestar. igualmente. o risco de captura das agências por parte dos particulares envolvidos no processo normativo.

Embora seja questionável a quantidade e natureza de quem efetivamente participa da atividade normativa das agéncias. é inegável a contribuição do procedimento negociado para uma maior participação pública.

\subsubsection{Principio da responsabilidade ("accoumability")}

Para tentar superar os inconvenientes dos amplos poderes delegados pelo Poder Legislativo às agencias. o Direito norte-americano idealizou diversos mecanismos de controle (diretos e indiretos) para rever e julg̨ar o produto da atuação das agências. Os agentes normativos são responsáveis perante os Poderes Legislativo, Executivo e Judiciário.

Warren diferencia quatro formas de fiscalização da atuação das agências pelo Congresso norte-americano, aduzindo que o mesmo possui poderes para 1) criar $\mathrm{c}$ organizar agências administrativas: 2) controlar o orçamento das agências; 3) investigar as atividades das ậencias: f) controlar a atuação das ag̣encias. através da aprovação de leis que condicionem o exercício da atividade. fixando coordenadas. como é o caso do $A P A^{711}$

Dentre as formas de controle direto sobre a atividade das agências. destaca-se o veto legislativo. o qual. para ser exercido requer previsão expressa na lei reguladora da agência. ${ }^{71}$ Trata-se de cláusula yue condiciona a entrada em vigor do regulamento à sua revisão e aprovação pelo Congresso. Logo. pode o Congresso aprovar. alterar ou vetar o texto do regulamento apresentado pela agência. ${ }^{72}$

69) Cf. Kerwin. p. 67. 106 a 167.

70 Warren. p. 157.

7t A primeira previsão de veto legislativo se incorporou no Economy Act. de 1932.

72 " The gencral purpose of the legislative veto is to provide Congress with an opportunity to block agency or presidential actions which legislators feel exceed statutory atuthority or are unsound." (Warren. p. 101.) O instituto do seto legislativo permite a legislador assumir o papel de efetivo supervisor dal Administraçió, de acordo com Schwartz. (Schwant. p. 220.) 
O veto legislativo é instituto dos mais criticados, por se entender que ele é inconstitucional.

Dentre os argumentos utilizados pelos seus opositores estão os seguintes: 1) violação ao princípio da separação de poderes; 2) desrespeito ao procedimento constitucional de aprovação de leis (bicameralismo, veto presidencial); 3) violação ao principio da participação dos particulares, vez que pode o Congresso introduzir modificaçōes no regulamento, após a manifestação do público. ${ }^{73}$

A Suprema Corte norte-americana já manifestou entendimento semelhante, no caso Immigration and Naturalization Service v: Chadha (1983). ao considerar que o veto legislativo foi inconstitucional. já que foi exercido apenas por uma das Câmaras do Poder Legislativo. com violação ao princípio do bicameralismo. ${ }^{74}$

Outras formas de fiscalização da atuação normativa foram instituídas pelo Corrections Calendar (1995) e pelo Small Business Regulatory Enforcement Fairness Act (1996), possibilitando que o Congresso corrija erro em regulamentos existentes e exigindo que os regulamentos sejam submetidos ao controle do Congresso e do General Accouming Office. respectivamente. ${ }^{75}$

Promulgado em 1996. o Congressional Review Act (CRA) fixou um mecanismo pelo qual o Congresso pode, em tese, rever e desaprovar todas as regras emanadas pelas agências federais. O CRA exige que as agências submetam aos dois órgãos representativos do Congresso norte-americano e ao Comptroller General (CG) a proposta das regras, acompanhada de sua descrição e seus motivos, e a data da proposta para o início de sua vigência. ${ }^{76}$

O Congresso também pode incidir indiretamente sobre a atuação das agências. Isto se verifica por meio da influência política exercida por ocasião da nomeação ou destituição de membros de cargos de direção das agências, dentre outras hipóteses.

A intervenção presidencial se desenvolve internamente tanto para coordenar as atividades das agências como para assegurar que se respeite a política geral do governo.

O Presidente do Estados Unidos atua diretamente no procedimento de nomeação ou destituição dos diretores das agências. Também intervém no procedimento normativo das agências. controlando-o e supervisionando-o por intermédio de medidas previstas em ordens executivas (executive orders). ${ }^{77}$

7.5 Subre o tema remetemos a Carbonell Porras e Muga Muñoz. p. 38 e 39.

74 Schwartz. p. 219.

75 Cf. Kerwin. p. 220.

in Rosenterg. Morton. Whatever happened to congressional review of agency rulemaking? a brief orervien: assessmem, and proposal for reform. In: Administrative Law Review. Chicago: American Bar Association, 1999, vol. 51. n 4. p. 1052 e 1053. O autor salienta que. desde abril de 1996 até o inicio de 1999 houve apenas oito vetos dentre as mais de 15.000 regras postas à apreciação do Congresso.

77 *O Presidente Clinton, através de uma ordem executiva, ordenou a submissão de todos os regulamentos considerados "significantes" à apreciação do OMB iOffice of Budget and Management). (Kerwin, p. 224.) 
O APA prevê a revisão jurisdicional da atividade normativa e decisória das agências

como a medida principal de controle de sua atuação. ${ }^{78}$

Quando a revisão da função normativa ou de seu resultado é admitida, ${ }^{79}$ abrange a apreciação de questões de direito e não de fato. apesar do $A P A$ prescrever um escopo mais amplo. ${ }^{80}$ Seu intuito é constatar a legalidade e constitucionalidade da atuação administrativa.

\section{Considerações finais}

1. No direito administrativo norte-americano as agências administrativas ocupam posição de destaque. estando a noção de direito administrativo diretamente vinculada à de agências administrativas;

2. A independência das agências administrativas reguladoras se manifesta principalmente através do exercício de poder normativo;

3. A função normativa das agências administrativas consiste em poder delegado pelo Legislativo para editar regulamentos;

4. O Administrative Procedure Act define três espécies de procedimentos normativos: informal, formal, negociado. A diferença fundamental entre eles concerne à forma de participação pública na sua elaboração.

5. As características do processo normativo podem ser resumidas em três princípios democráticos: informação (publicidade), participação e controle.

6. Os princípios da informação e da participação estão estreitamente relacionados. pois referem-se à oportunidade que deve ser dada aos particulares, para que participem do processo normativo, elaborando sugestões ou fornecendo documentos.

7. A doutrina norte-americana destaca que se tem procurado proporcionar maior participação popular nos processos normativos das agências, por intermédio. por exemplo, do Procedimento Negociado, a fim não somente de legitimar o processo normativo, mas igualmente para que haja aprimoramento do conteúdo das normas a serem editadas.

78 O tema da revisão judicial (judicial revieu ) é tratado amplamente pela doutrina norte-americana e poderia ser objeto de um estudo a parte. Para uma análise pormenorizada do tema, remetemos às obras de Kerwin: Schwartz: Carbonell Porras e Muga Muñoz: Bonfield e Asimow: Breyer e Stewart. 79 "Agency action made reviewable by statute and final agency action for which there is no other adequate remedy in a court are subject to judicial review. A preliminary, procedural or intermediate agency action or ruling not directly reviewable is subject to review on the review of the final agency action." (Seção 704 do APA)

80 "To the extent necessary to decision and when presented, the reviewing court shall decide all relevant questions of law. interpret constitutional and statutory provisions, and determine the meaning or applicability of the terms of an agency action." (Seção 706 do APA) 
8. Críticas são formuladas à forma de participação dos particulares no processo normativo, em razâo da qualidade da mesma (na maioria das vezes baixa). porque somente uma pequena parcela da população efetivamente participa do processo. devido ao risco de captura das agências por interesses privados e pelo fato de que as agências não são obrigadas a adotar as sugestões formuladas.

9. No intuito de fiscalizar a atuação das agências, procura-se controlá-las por meio de mecanismos utilizados pelos Poderes Executivo, Legislativo e Judiciário, além do controle social que pode ser efetuado através da participação dos particulares no processo de atuação das agências.

\section{Referências bibliográficas}

BETANCOR RODRÍGUEZ, Andrés. Las administraciones independientes. Madrid: Tecnos, 1994.

Black's law dictionary. 6. ed. St. Paul: West Publishing Co.

BONFIELD, Arthur E.; ASIMOW, Michael. State and federal administrative law. St. Paul: West Publishing Co., 1989.

BREYER, Stephen; STEWART, Richard B. Administrative law and regulatory policy: Problems, text and cases. 3.ed. [S.l.] Little, Brown and company.

CARBONELL PORRAS, Eloísa; MUGA MUÑOZ, José Luis. Agencias y procedimiento administrativo en Estados Unidos de América. Madrid: Marcial Pons, 1996.

CHIRILlO, Eduardo J. Rodríguez. Privatización de la empresa pública y post privatización. Buenos Aires: Abeledo-Perrot, 1995.

DE LA SIERNA BILBAO, Maria Nieves. La privatización en España: fundamentos constitucionales y comunitarios. Pamplona: Aranzadi, 1995.

DI PIETRO, Maria Sylvia Zanella. Direito administrativo. 10 ed. São Paulo: Atlas, 1999.

DINIZ, Maria Helena. Dicionário jurídico. Vol. 2. São Paulo: Saraiva, 1998.

KERWIN, Cornelius. Rulemaking: How government agencies write law and make policy. 2 ed. Washington: Congressional Quarterly Inc., 1999.

LAWSON, Gary. Federal administrative law'. St. Paul: West Group, 1998.

LORCH, Robert S. Democratic process and administrative law. Detroit: Wayne State University Press, 1980.

Merriam Webster's dictionary of law. Springfield: Merriam-Webster, 1996.

MOREIRA, Vital. Auto-regulação profissional e administraçāo pública. Coimbra: Almedina, 1997.

- Autoridades reguladoras independentes (ARI) nos domínios económico e financeiro: estudo e projecto de lei-quadro. Portugal. Ministério da Reforma do Estado e da Administração Pública, 2002.

MORENO MOLINA, Ángel Manuel. La administración por agencias en los Estados Unidos de America. Madrid: Marcial Pons, [s.d.].

PEREIRA, Luiz Carlos Bresser. Reforma do Estado para a cidadania: A reforma gerencial brasileira na perspectiva internacional. São Paulo: Editora 34, 1998. 
ROSENBERG. Morton. Whatever happened to congressional review of agency rulemaking?: a brief overvien', assessment, and proposal for reform. In: Administrative Law Review. Chicago: American Bar Association. 1999, vol. 51, n. 4. p. 1.052 e 1.053 .

SCHWARTZ. Bernard. Administrative law: 3.ed. Boston: Little. Brown and Company.

SISUNG, Kelle (Ed.) Federal agencies profiles for students. Detroit: Gale. 1999.

SWANN. Dennis. The retreat of the state: (Deregulation and privatization in the UK and US). [S.1.] The University of Michigan Press. 1991.

WARREN. Kenneth F. Administrative law in the political sustem. 3.ed. Upper Saddle River: Prentice-Hall, 1996. 